\title{
Synthesis, Characterization of Immobilized Thiosalicylic-Mercaptoethanol Bi-Ligand System and its Application in Detoxification of Chromium III and Iron III ions from Tannery Wastewater
}

\author{
Bulus Habila, Pius Onyeoziri Ukoha, Stanley I.R. Okoduwa, Ahmed Salim, Muazu B. Babangida, Adamu \\ Simon
}

Submitted date: 04/10/2019 Posted date: 04/10/2019

Licence: CC BY-NC-ND 4.0

Citation information: Habila, Bulus; Ukoha, Pius Onyeoziri; Okoduwa, Stanley I.R.; Salim, Ahmed; Babangida, Muazu B.; Simon, Adamu (2019): Synthesis, Characterization of Immobilized Thiosalicylic-Mercaptoethanol Bi-Ligand System and its Application in Detoxification of Chromium III and Iron III ions from Tannery Wastewater. ChemRxiv. Preprint.

Background: Effective wastewater treatments are paramount to modern-day Scientists. The available methods are ineffective in detoxifying tannery wastewater. Aim: This study synthesize and characterized polysiloxane-Immobilized thiosalicylic-mercaptoethanol ligand system (PITSMCBLS) and used in detoxification of $\mathrm{Cr} 3+$ and Fe3+ from tannery wastewater.Method: Porous solid PITSMCBLS was prepared by hydrolytic polycondensation of tetraethylorthosilicate with mixture of 3-chloropropyltrimethoxysilane, methanol and sodium hydroxide as catalyst. The gelation formed (3-CPP) after $40 \mathrm{~min}$, was functionalized (F-3CPP) with excess ethylchloroacetate, triethylamine and grafted with thiosalicylic-mercaptoethanol bi-ligand. The PITSMCBLS was characterized using FTIR and SEM-EDX. The competitive sorption characteristics of metal ions (Cr3+ and Fe3+) were studied using Microwave Plasma Atomic-Emission Spectrophotometer.Result: The FTIR spectrum of PITSMCBLS showed vibrational frequencies (cm-1) at: 3339, (O-H); 2928, (C-H); 2685, (SH); 2497, (Si-H); 1587-1707, (C=O) and 1028, (Si-O). The SEM-EDX showed irregular particle sizes $(4.4294 \pm 1.7187 \mathrm{~nm})$ and elemental composition (wt \%): 3-CPP, Si (50.45); O (25.02) and Cl (24.57). The F-3CPP showed, O (58.68) and Si (41.32), while PITSMCBLS showed 11.94 of S. Gibbs free energy yielded negative range values for $\Delta \mathrm{Go}(\mathrm{Cr} 3+-14.187$ to -14.832 and Fe3+ - 14.369 to $-14.843 \mathrm{kJmol}-1)$, positive values for: $\Delta \mathrm{Ho}(\mathrm{Cr} 3+5.345$ and Fe3+ $0.000 \mathrm{kJmol}-1)$ and $\Delta \mathrm{So}(\mathrm{Cr} 3+64.459$ and Fe3+ $47.421 \mathrm{Jmol} 1 \mathrm{~K} 1)$ respectively.Conclusion: PITSMCBLS exhibits high potential for extraction of Cr3+ and Fe3+ in tannery wastewater. The Thermodynamic values indicate spontaneous, endothermic reactions and high degree of disorderliness with respect to metal ion binding capacity to the ligand system. This development would improve tannery wastewater treatment.

File list (2) 
Synthesis_Characterization_of_Immobilized_Thiosalic... (266.29 KiB) view on ChemRxiv • download file 


\title{
Synthesis, Characterization of Immobilized
} Thiosalicylic-Mercaptoethanol Bi-Ligand System and Its Application in Detoxification of Chromium III and Iron III lons from Tannery Wastewater

\author{
Bulus Habila, Pius Onyeoziri Ukoha, Stanley I.R. Okoduwa, Ahmed Salim, Muazu B. Babangida, Adamu \\ Simon
}

Submitted date: 30/09/2019 - Posted date: 02/10/2019

Licence: CC BY-NC-ND 4.0

Citation information: Habila, Bulus; Ukoha, Pius Onyeoziri; Okoduwa, Stanley I.R.; Salim, Ahmed; Babangida, Muazu B.; Simon, Adamu (2019): Synthesis, Characterization of Immobilized Thiosalicylic-Mercaptoethanol Bi-Ligand System and Its Application in Detoxification of Chromium III and Iron III Ions from Tannery Wastewater. ChemRxiv. Preprint.

Background: Effective wastewater treatments are paramount to modern-day Scientists. The available methods are ineffective in detoxifying tannery wastewater. Aim: This study synthesize and characterized polysiloxane-Immobilized thiosalicylic-mercaptoethanol ligand system (PITSMCBLS) and used in detoxification of $\mathrm{Cr} 3+$ and $\mathrm{Fe} 3+$ from tannery wastewater.Method: Porous solid PITSMCBLS was prepared by hydrolytic polycondensation of tetraethylorthosilicate with mixture of 3-chloropropyltrimethoxysilane, methanol and sodium hydroxide as catalyst. The gelation formed (3-CPP) after $40 \mathrm{~min}$, was functionalized (F-3CPP) with excess ethylchloroacetate, triethylamine and grafted with thiosalicylic-mercaptoethanol bi-ligand. The PITSMCBLS was characterized using FTIR and SEM-EDX. The competitive sorption characteristics of metal ions ( $\mathrm{Cr} 3+$ and $\mathrm{Fe} 3+$ ) were studied using Microwave Plasma Atomic-Emission Spectrophotometer.Result: The FTIR spectrum of PITSMCBLS showed vibrational frequencies (cm-1) at: 3339, (O-H); 2928, (C-H); 2685, (SH); 2497, ( $\mathrm{Si}-\mathrm{H}) ;$ 1587-1707, $(\mathrm{C}=\mathrm{O})$ and 1028, (Si-O). The SEM-EDX showed irregular particle sizes (4.4294 $\pm 1.7187 \mathrm{~nm}$ ) and elemental composition (wt \%): 3-CPP, Si (50.45); O (25.02) and Cl (24.57). The F-3CPP showed, O (58.68) and Si (41.32), while PITSMCBLS showed 11.94 of S. Gibbs free energy yielded negative range values for $\Delta \mathrm{Go}$ ( $\mathrm{Cr} 3+-14.187$ to -14.832 and Fe3+ -14.369 to $-14.843 \mathrm{kJmol}-1$ ), positive values for: $\Delta \mathrm{Ho}(\mathrm{Cr} 3+5.345$ and Fe3+ $0.000 \mathrm{kJmol}-1)$ and $\Delta \mathrm{So}(\mathrm{Cr} 3+64.459$ and Fe3+ $47.421 \mathrm{Jmol} 1 \mathrm{~K} 1)$ respectively.Conclusion: PITSMCBLS exhibits high potential for extraction of $\mathrm{Cr} 3+$ and $\mathrm{Fe} 3+$ in tannery wastewater. The Thermodynamic values indicate spontaneous, endothermic reactions and high degree of disorderliness with respect to metal ion binding capacity to the ligand system. This development would improve tannery wastewater treatment.

File list (2) 
1Synthesis, Characterization of Immobilized Thiosalicylic-Mercaptoethanol Bi-Ligand 2System and its Application in Detoxification of Chromium III and Iron III ions from 3Tannery Wastewater

4

5Bulus Habila ${ }^{1,2, *}$, Pius Onyeoziri Ukoha², Stanley I.R. Okoduwa ${ }^{1}$, Ahmed Salim¹, Muazu B. 6Babangida ${ }^{1}$, Adamu Simon ${ }^{1}$

7

$8^{1}$ Directorate of Research and Development, Nigerian Institute of Leather and Science 9

10 Technology, Zaria, Nigeria

$11^{2}$ Department of Pure and Industrial Chemistry, University of Nigeria, Nsukka, Nigeria

12*Correspondence: Email: bulus1973@gmail.com; Tel: +234-803-075-8059

13

\section{Abstract}

15Background: Effective wastewater treatments are paramount to modern-day Scientists. The 16available methods are ineffective in detoxifying tannery wastewater.

17Aim: This study synthesize and characterized polysiloxane-Immobilized thiosalicylic18mercaptoethanol ligand system (PITSMCBLS) and used in detoxification of $\mathrm{Cr}^{3+}$ and $\mathrm{Fe}^{3+}$ 19from tannery wastewater.

20Method: Porous solid PITSMCBLS was prepared by hydrolytic polycondensation of 21tetraethylorthosilicate with mixture of 3-chloropropyltrimethoxysilane, methanol and sodium 22hydroxide as catalyst. The gelation formed (3-CPP) after $40 \mathrm{~min}$, was functionalized (F233CPP) with excess ethylchloroacetate, triethylamine and grafted with thiosalicylic24mercaptoethanol bi-ligand. The PITSMCBLS was characterized using FTIR and SEM-EDX. 25The competitive sorption characteristics of metal ions $\left(\mathrm{Cr}^{3+}\right.$ and $\left.\mathrm{Fe}^{3+}\right)$ were studied using 26Microwave Plasma Atomic-Emission Spectrophotometer. 
27Result: The FTIR spectrum of PITSMCBLS showed vibrational frequencies $\left(\mathrm{cm}^{-1}\right)$ at: 3339, 28(O-H); 2928, (C-H); 2685, (SH); 2497, (Si-H); 1587-1707, (C=O) and 1028, (Si-O). The 29SEM-EDX showed irregular particle sizes $(4.4294 \pm 1.7187 \mathrm{~nm})$ and elemental composition (wt \%): 303-CPP, Si (50.45); O (25.02) and Cl (24.57). The F-3CPP showed, O (58.68) and Si (41.32), while 31PITSMCBLS showed 11.94 of S. Gibbs free energy yielded negative range values for $\Delta \mathrm{G}^{\circ}$ 32( $\mathrm{Cr}^{3+}-14.187$ to -14.832 and $\mathrm{Fe}^{3+}-14.369$ to $\left.-14.843 \mathrm{kJmol}^{-1}\right)$, positive values for: $\Delta \mathrm{H}^{\mathrm{o}}\left(\mathrm{Cr}^{3+}\right.$ 335.345 and $\left.\mathrm{Fe}^{3+} 0.000 \mathrm{kJmol}^{-1}\right)$ and $\Delta \mathrm{S}^{\circ}\left(\mathrm{Cr}^{3+} 64.459\right.$ and $\left.\mathrm{Fe}^{3+} 47.421 \mathrm{Jmol}^{1} \mathrm{~K}^{1}\right)$ respectively.

34Conclusion: PITSMCBLS exhibits high potential for extraction of $\mathrm{Cr}^{3+}$ and $\mathrm{Fe}^{3+}$ in tannery 35wastewater. The Thermodynamic values indicate spontaneous, endothermic reactions and 36high degree of disorderliness with respect to metal ion binding capacity to the ligand system. 37This development would improve tannery wastewater treatment.

38Keywords: Tannery wastewater; Detoxification; Polysiloxane; Thiosalicylic39 mercaptoethanol ligand; Thermodynamic.

\section{Introduction}

42Leather industries play very significant role in the economy of many countries, but also 43generate harmful wastes into water bodies (Bulus et al., 2018; Igiri et al., 2018; Evangelo and 44Ebel, 2007). The harmful wastes are generated from cleaning, fleshing, splitting, tanning, 45shaving and buffing of raw hides or skins (Onukak et al., 2017). These waste materials in 46water bodies' results in environmental risks associated with health hazard (Okoduwa et al, 472017, 2019). Several living organisms in ecosystem including human have suffered severe 48toxicity threat emanating from untreated discharged of tanning chemicals in the environment 49(Okoduwa, et al 2019; Igiri et al., 2018; Okolo et al., 2016). During tanning alone about 300 $50 \mathrm{~kg}$ of chemicals are added per ton of hides or skins (Durai and Rajasimman 2001). 51Additionally, large volume of water, $35 \mathrm{~L}$ is consumed per kilogram of raw hide or skin 
52processed and an average of 35,000 L of wastewater is produced per ton of raw hide or skin 53(Islam et al., 2014). Not more than 20\% of the chemicals used are absorbed by leather; the 54remainder flows out with the effluent causing environmental pollution when discharged 55untreated or partially treated (Muthukkauppan and Parthiban, 2018). These resultant 56wastewaters that are discharged contain toxic metallic components such as $\mathrm{Cr}^{6+}, \mathrm{Fe}^{3+}, \mathrm{Cd}^{2+}$, 57 $\mathrm{Cu}^{2+}$ (Machado et al., 2009). Some of these toxic heavy metals are difficult to detoxify (Islam 58et al., 2014). Conventional methods used in the tannery wastewater treatments include 59electrochemical treatment, coagulation/flocculation, activated sludge process and sequential 60batch reactor (Ayoub et al., 2011; Ganesh et al., 2006). All these technologies have 61limitations such as production of toxic sludge (Jahan et al., 2014) and inability to remove 62heavy metals at trace level. It is therefore imperative to develop innovative technologies 63which require low maintenance, high energy efficiency, low cost and better operational 64techniques than the conventional methods. This prompted the use of polymeric modified 65surfaces with excellent thermal, mechanical and chemical stability properties such as 66polysiloxane functionalized or immobilized with ligands (El- Ashgar, 2009). Although they 67have been employed as a recyclable extractant for heavy metals and in stationary phases in 68chromatographic techniques using simulated water but have not been used nor investigated 69on tannery wastewater. The immobilized ligand system could be synthesized directly by sol 70gel or by chemical modification of prepared functionalized polysiloxane (El- Ashgar, 2009; 712012). A variety of spectroscopic techniques such as Fourier Transform Infra-red (FTIR) (Issa 72et al., 2002; Nizam and Salman, 2006), Nuclear Magnetic Resonance (NMR), Scanning 73Electron Microscopy (SEM) (Abdussalam et al., 2012; Piotr et al., 2016) and Energy 74Dispersive X-ray Analysis (EDX) (Abdussalam et al., 2012; Piotr et al., 2016), have been 75employed to study the ligand modified polysiloxane systems. This study therefore described 
76the synthesis and characterization of polysiloxane-Immobilized thiosalicylic acid ligand 77system and its potential in the detoxification of tannery wastewater.

\section{Materials and Methods}

\subsection{Reagents and Chemicals}

80Tetraethylorthosilicate, 3-chloropropyltrimethoxysilane, thiosalicylic acid and methanol, 81where purchased from Sigma-Aldrich Chemical Company and used without further 82purification. Triethylamine, ethylchloroacetate, sodium hydroxide (LOBA Chemie). Diethyl 83ether (spectroscopic grade). Different $\mathrm{pH}$ values in the range of 2.0 - 9.0 were controlled 84using $0.1 \mathrm{Mol} / \mathrm{dm}^{3} \mathrm{HCl}$ and $\mathrm{NaOH}$ (Carson 2000pH Model) respectively.

852.2 Synthesis of Polysiloxane Immobilized Thiosalicylic / Mercaptoethanol Bi-Ligand System 86Immobilization of thiosalicylic/mercaptoethanol ligand was carried out with respect to the 87methods of El- Nahhal et al., (2002); Salman and Nizam (2006) and Nizam, (2008), with 88modifications. The functionalized product, was measured (3.200g) and added to (0.05 mol; 89density $1.49 \mathrm{~g} / \mathrm{cm}^{3} ; 7.959 \mathrm{~g}$ and $0.05 \mathrm{~mol}$; density $1.114 \mathrm{~g} / \mathrm{cm}^{3}$; volume $3.50 \mathrm{~cm}^{3}$ ) 90thiosalicylic and mercaptoethanol respectively in ethyl-chloroacetate $(0.244 \mathrm{~mol}$; density $911.145 \mathrm{~g} / \mathrm{cm}^{3}$; volume $26.20 \mathrm{~cm}^{3}$ ) and $5 \mathrm{~cm}^{3}$ of triethylamine in a round-bottomed flask $92\left(250 \mathrm{~cm}^{3}\right)$ and refluxed for $12 \mathrm{~h}$ at $110^{\circ} \mathrm{C}$ the product formed was filtered, washed 93successively with $50 \mathrm{~cm}^{3}$ portions of de-ionized water, methanol and diethyl ether, dried at $94110^{\circ} \mathrm{C}$ in an oven for $10 \mathrm{~h}$, labelled and dried over $\mathrm{CaCl}_{2}$.

\subsection{Digestion of Tannery Wastewater}

96Tannery wastewater sample of $1000 \mathrm{~cm}^{3}$ was transferred into a conical flask and evaporated 97till dried. The dried sample was digested in 10:1 $\mathrm{HNO}_{3}: \mathrm{HClO}_{4}(\mathrm{v} / \mathrm{v})$. White crystals were 98found in the digested samples and were dissolved in $150 \mathrm{ml}$ de-ionized water. The 
99supernatants were filtered using Whatman No.41 filter paper and were read directly with 100Agilent MPAES-4200 (Shahida et al., 2017).

101

1022.4 Thermodynamic Studies and Effect of Adsorbent

103A volume of $60 \mathrm{~cm}^{3}$ solution of the tannery wastewater adjusted at $\mathrm{pH} 6$ (optimum) was 104transferred into $150 \mathrm{~cm}^{3}$ conical flask and $10 \mathrm{mg}$ of the PITSMCBLS was added and adjusted 105in a thermostatic multi-shaker at $100 \mathrm{rpm}$ for $2 \mathrm{~h}$ at $30{ }^{\circ} \mathrm{C}$. The resultant solutions were 106filtered using Whatman No.41 and the residual metal concentrations analysed $\left(\mathrm{Cr}^{3+}\right.$ and $\left.\mathrm{Fe}^{3+}\right)$ 107using Agilent MPAES-4200 (Bernard and Jimoh 2013; Senthil and Kirthika, 2009; Horsfall 108et al., 2006) This procedure was repeated for 20 and $30 \mathrm{mg}$ of PITSMCBLS respectively and 109at temperatures of 35 and $40{ }^{\circ} \mathrm{C}$ respectively.

\section{Results and Discussion}

111The leather industry contributes immensely in the generation of wastewater without proper 112treatment thereby contaminating or polluting the eco-system (Okoduwa, et al., 2019). Hence 113the use of PITSMCBLS was employed to adsorbed heavy metals $\left(\mathrm{Cr}^{3+}\right.$ and $\left.\mathrm{Fe}^{3+}\right)$ present in 114the wastewater. This was made possible due to the availability of reactive sites in the 115polysiloxane matrix in Scheme 1 and the mechanism of the reaction in Scheme 2. The 116mechanism could be surface adsorption or chemisorption. The protonation of $\mathrm{COOH}$ to $\mathrm{COO}^{-}$ 117by triethylamine, $\mathrm{SH}$ to $\mathrm{S}^{-}$, and the presence of oxy ions contributes to the adsorption of these 118heavy metals. 

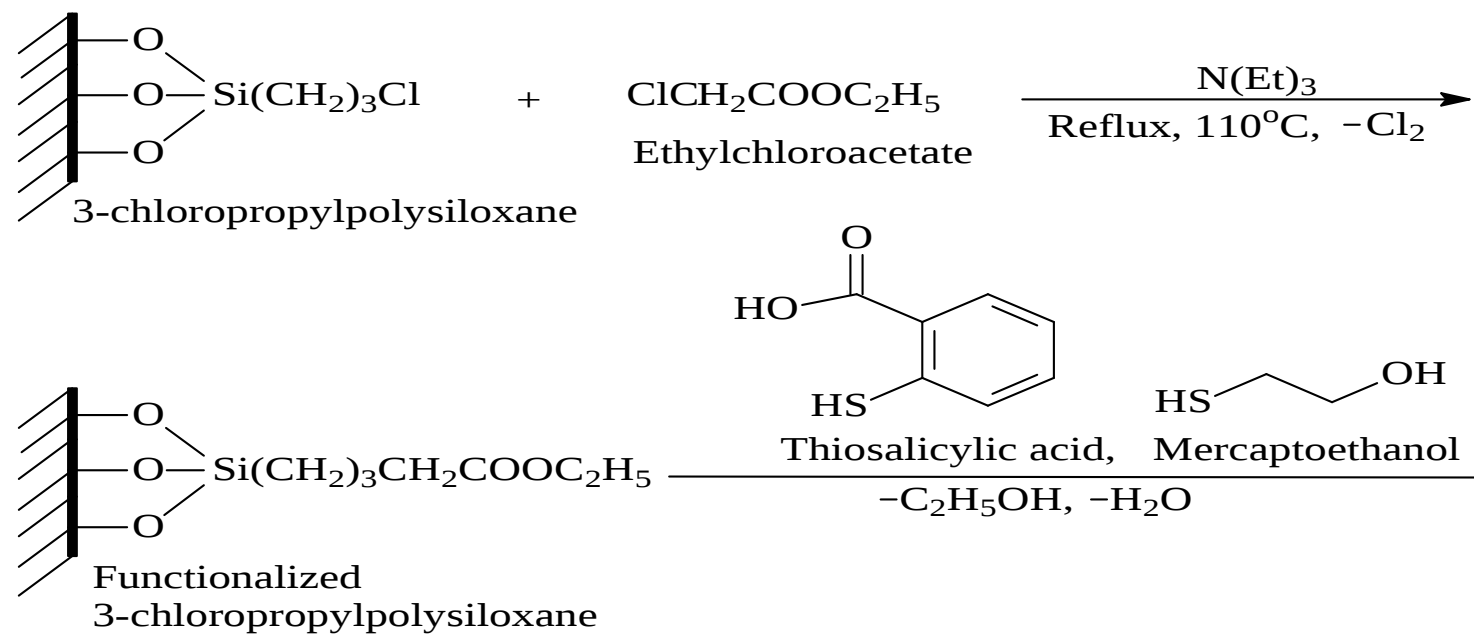<smiles>O=C(O)c1ccccc1S</smiles><smiles>OCCS</smiles>
Thiosalicylic acid, Mercaptoethanol $-\mathrm{C}_{2} \mathrm{H}_{5} \mathrm{OH},-\mathrm{H}_{2} \mathrm{O}$

3-chloropropylpolysiloxane<smiles>C#CC1(C)OC2(CC)O[Si](CC)(CC)O[Si](C)(O1)O2</smiles>

121Scheme 1: Synthesis of polysiloxane immobilized thiosalicylic-mercaptoethanol bi-ligand system.

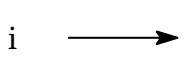

Mono-Ligand

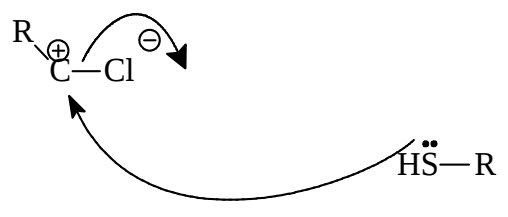

ii

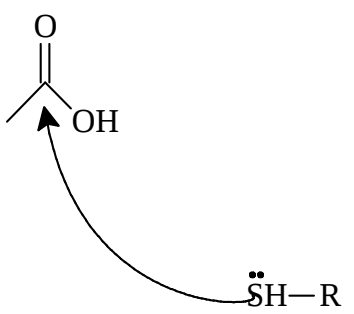

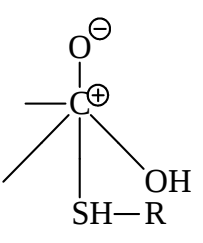

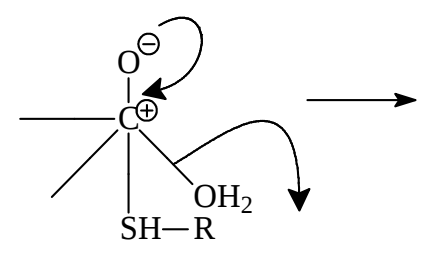<smiles>[R]SC(C)=O</smiles>

Bi-Ligand

127Scheme 2: Reaction mechanism for polysiloxane immobilized thiosalicylic/mercaptoethanol 
1313.1 SEM/EDX Analysis for polysiloxane Immobilized Thiosalicylic/Mercaptoethanol Bi132 ligand System

133The SEM (EVO/LS10 ZEISS) showed irregular particle sizes of the following polysiloxane 134matrices at various magnifications $(\mu \mathrm{m})$ : 3- chloropropylpolysiloxane (500); functionalized 1353-chloropropylpolysiloxane $(500 \mu \mathrm{m})$ and PITSMCBLS $(200 \mu \mathrm{m})$ in Plate I, with the EDX 136(EVO/LS10 ZEISS) elemental composition in that order (wt \%); 3-CPP; Si (50.45), O 137(25.02) and Cl (24.57); F-3-CPP; O (58.68), Si (41.32) (Abdussalam et al., 2012) the ligand 138was introduced after polymerization by nucleophilic displacement of a halide anion (Brad et 139al., 2009) and the \% weight (Sulphur) of PITSMCBLS gave 11.93in Plate I. The value was 140obtained because of the availability of reactive sites in nano sizes which is shown in Table 1, 141which assisted in the immobilization process, with mean and standard deviation of $4.4294 \pm$ 1421.7187 nm for immobilized PITSMCBLS. This is in agreement with the nano particle sizes of 143silica at the range of 2-5 nm (El-Nahhal and El-Ashgar, 2007) with an extraordinary surface144to-volume ratio. Pore volume of $100.1614 \pm 101.3491 \mathrm{~nm}^{3}$ was obtained, which played a vital 145role in adsorption of heavy metals in the tannery wastewater. The Sulphur in PITSMCBLS 146which was not present originally in the synthesized 3-CPP and the Functionalized 3-CPP 147confirmed its immobilization to the matrix. The wt \%: 11.94 was above the range of 6.1-10.4 148reported by Issa et al., (2010); 8.0, El-Ashgar (2009); 4.30-11.30 (Issa et al., 2015); 3.901496.80 (Mona et al., 2016) for similar synthesis. The presence of Sulphur in the matrix is in 150consonant with the FTIR (C 620 Agilent Technology) results with vibrational frequencies 151( $\left.\mathrm{cm}^{-1}\right)$ as shown in Figure 1: alcohol $(\mathrm{O}-\mathrm{H}, 3339)$, alkane (C-H, 2928) thiol $(\mathrm{SH}, 2685)$; 152silane (Si-H, 2497), carbonyl (C=O, 1587.8 - 1707) and siloxane (Si-O, 1028) respectively. 


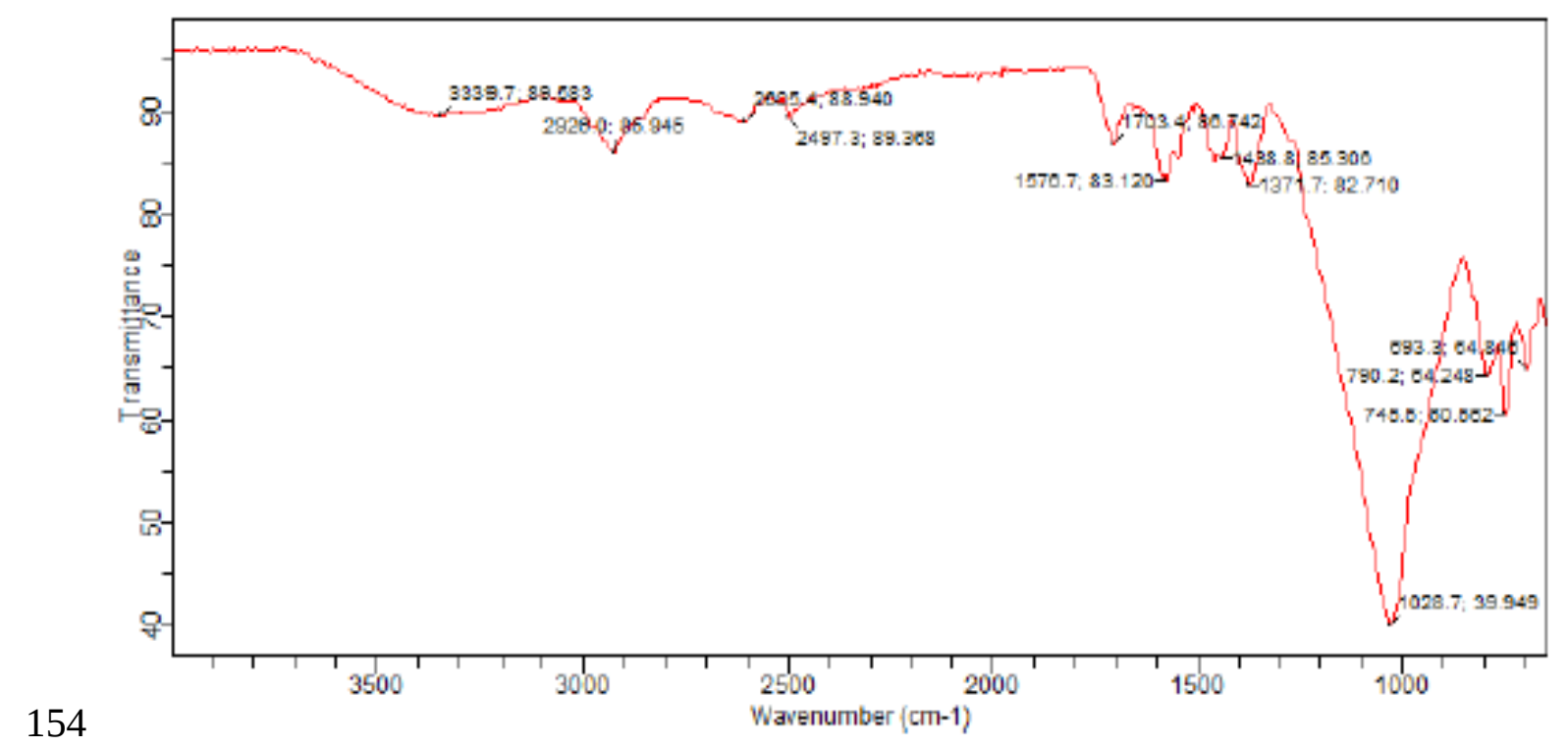

155Figure 1: FTIR Spectrum for Polysiloxane Immobilized Thiosalicylic-Mercaptoethanol Bi$156 \quad$ Ligand System

157

1583.2 Effect of Polysiloxane Immobilized Thiosalicylic/Mercaptoethanol Bi-Ligand Dose on 159

160 the Adsorption of Heavy Metals

161The adsorption effects of various weights of the adsorbent from 10 to $30 \mathrm{mg} / 60 \mathrm{~cm}^{3}$ were 162used for the extraction of metal ion in Table 1. All the mass showed significant extraction of 163the metal ions. The $\mathrm{Cr}^{3+}$ percentage adsorption decreases with increase in the amount of 164adsorbent while $\mathrm{Fe}^{3+}$ showed no significant increase with increased in the amount of 165adsorbent in the treated tannery wastewater.
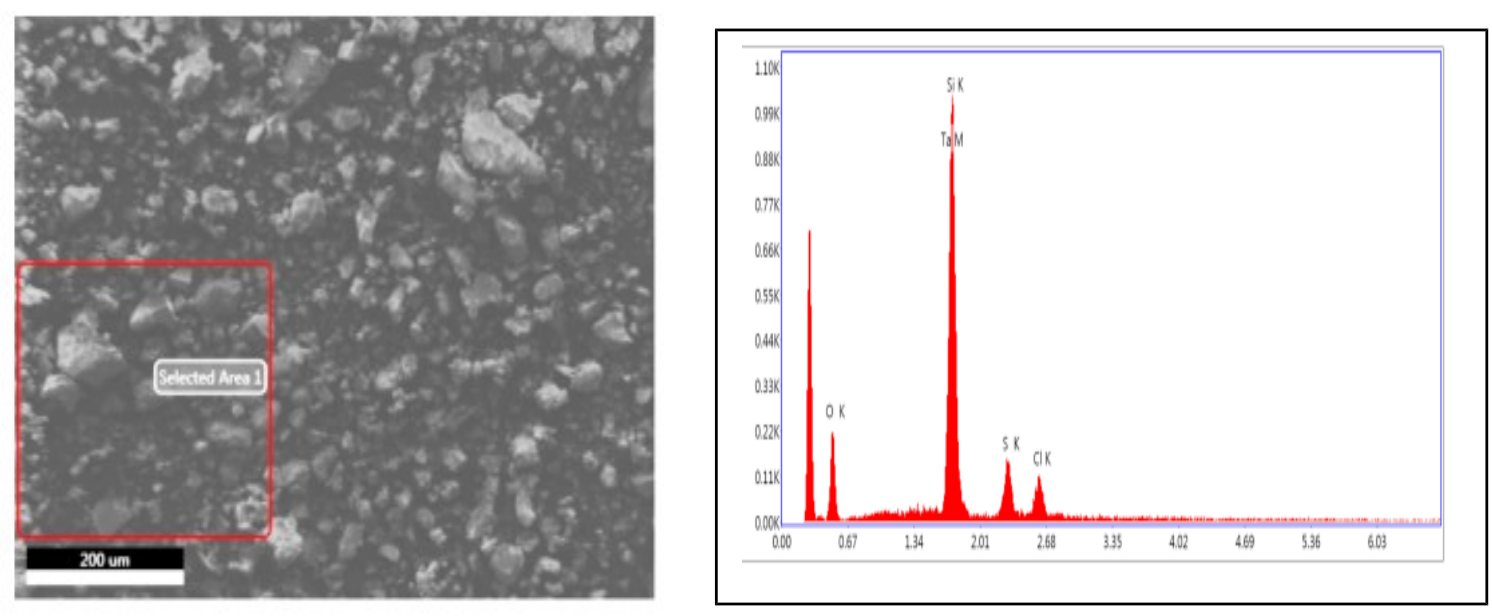
167Plates 1: $\quad$ SEM/EDX, Morphology and Elemental Composition for Poliysiloxane 168 Immobilized Thiosalicylic/Mercaptoethanol Bi-Ligand System.

169

170Table 1: Polysiloxane Immobilized Thiosalicylic/Mercaptoethanol Ligand Particle Size 171 Results.

\begin{tabular}{|c|c|c|c|c|c|c|c|c|}
\hline & Area(nm) & Mean & Min & Max & $\mathbf{r}^{2}$ & $r(\mathrm{~nm})$ & d (nm) & $\mathrm{v}\left(\mathrm{nm}^{3}\right)$ \\
\hline Mean & 17.7193 & 255 & 255 & 255 & 5.6402 & 2.2147 & 4.4294 & 100.1614 \\
\hline Standard Error & 0.8505 & 0 & 0 & 0 & 0.2707 & 0.0569 & 0.1138 & 6.7120 \\
\hline Median & 16 & 255 & 255 & 255 & 5.0929 & 2.2567 & 4.5135 & 72.2162 \\
\hline Mode & 4 & 255 & 255 & 255 & 1.2732 & 1.1283 & 2.2567 & 9.0270 \\
\hline Standard Deviation & 12.8423 & 0 & 0 & 0 & 4.0878 & 0.8593 & 1.7187 & 101.3491 \\
\hline Sample Variance & 164.9253 & 0 & 0 & 0 & 16.7104 & 0.7385 & 2.9541 & 10271.64 \\
\hline Range & 44 & 0 & 0 & 0 & 14.0056 & 2.7804 & 5.5608 & 366.2197 \\
\hline Minimum & 4 & 255 & 255 & 255 & 1.2732 & 1.1283 & 2.2567 & 9.0270 \\
\hline Maximum & 48 & 255 & 255 & 255 & 15.2788 & 3.9088 & 7.8176 & 375.2467 \\
\hline Sum & 4040 & 58140 & 58140 & 58140 & 1285.9719 & 504.954 & 1009.9079 & 22836.8 \\
\hline $\begin{array}{l}\text { Count } \\
\text { Confidence Level }\end{array}$ & 228 & 228 & 228 & 228 & 228 & 228 & 228 & 228 \\
\hline$(95.0 \%)$ & 1.6758 & 0 & 0 & 0 & 0.5334 & 0.1121 & 0.2242 & 13.2258 \\
\hline
\end{tabular}

173

174Table 2: Effect of Immobilized Thiosalicylic/Mercaptoethanol Bi-Ligand Dose on the $175 \quad$ Adsorption of Heavy Metals

METAL BLANKS

$\begin{array}{lllllll} & \mathbf{A} & -0.014 & & \mathbf{1 0} & \mathbf{2 0} & \mathbf{3 0} \\ & \mathbf{B} & -0.034 & \mathbf{C i a} & 10.952 & 10.952 & 10.952 \\ \mathbf{C r}(\mathbf{p p m}) & \mathbf{T b} & & \mathbf{C i b} & 10.952 & 10.952 & 10.952 \\ & & & \mathbf{C f a} & 0.304 & 0.328 & 0.127 \\ & & & \mathbf{C f b} & 0.304 & 0.328 & 0.127 \\ & \mathbf{A} & -52.477 & & & & \\ & \mathbf{B} & -61.983 & \mathbf{C i a} & 0.328 & 0.328 & 0.328 \\ \mathbf{F e}(\mathbf{p p m}) & \mathbf{T b} & & \mathbf{C i b} & 0.328 & 0.328 & 0.328 \\ & & & \mathbf{C f a} & -0.190 & -0.327 & -1.354 \\ & & & \mathbf{C f b} & 0.000 & 0.000 & 0.000 \\ & & & \mathbf{\% A D S} & 100.000 & 100.000 & 100.000\end{array}$

$176 \mathrm{~A}=$ de-ionized water; $\mathrm{B}=$ sample blank; $\mathrm{rC}_{\mathrm{oi}}=$ relative initial concentration; $\mathrm{rC}_{\mathrm{ef}}=$ relative final concentration; $\% \mathrm{ADS}=$ 177percentage adsorption 
1793.3 Thermodynamic Study of Polysiloxane Immobilized Thiosalicylic/Mercaptoethanol Bi$180 \quad$ Ligand System

181The distribution coefficients, $\mathrm{K}_{\mathrm{D}}$ for the extraction of $\mathrm{Cr}^{3+}$ and $\mathrm{Fe}^{3+}$ metal ions from solutions 182of tannery wastewater by PITSMCBLS was studied at different temperatures of 30, 35 and 40 $183^{\circ} \mathrm{C}$ (Table 3). The results for $\mathrm{Cr}^{3+}$ showed that the distribution coefficients $\mathrm{K}_{\mathrm{D}}$ increased with 184increase in temperature because the rate of adsorbate diffusion across the external boundary 185layer and in the internal pores of the adsorbate particles increases with increase in 186temperature with a resultant decrease in liquid viscosity while $\mathrm{Fe}^{3+}$ showed no significant 187change with increase in temperature. In order to determine the thermodynamic feasibility and 188the thermal effects of sorption, the thermodynamic parameters were evaluated using $\Delta \mathrm{G}^{\circ}=$ 189-RT InK $K_{D}$ and $\Delta \mathrm{G}^{\circ}=\Delta \mathrm{H}^{\circ}-\mathrm{T} \Delta \mathrm{S}^{\circ}$, where $\Delta \mathrm{G}^{\circ}, \Delta \mathrm{H}^{\circ}, \Delta \mathrm{S}^{\circ}$ and $\mathrm{T}$ are Gibbs free energy, 190enthalpy, entropy and absolute temperature respectively (El-Ashgar, 2009; Parimalam et al., 1912011). $R$ is the gas constant $\left(8.314 \mathrm{Jmol}^{-1} \mathrm{~K}^{-1}\right.$ ) and $K_{D}$ is the equilibrium constant. Plots of $\operatorname{InK}_{D}$ 192against $1 / \mathrm{T}$ gave the numerical values of $\Delta \mathrm{H}^{\circ}$ and $\Delta \mathrm{S}^{\circ}$ from slope and intercept respectively 193(Rajashree et al., 2012). The values of $\Delta \mathrm{G}^{0}, \Delta \mathrm{H}^{\circ}$ and $\Delta \mathrm{S}^{0}$ are given for $\mathrm{Cr}^{3+}$ and $\mathrm{Fe}^{3+}$ in Table 1942. The negative values of the Gibbs free energy $\Delta \mathrm{G}^{\circ}$ for all temperatures with appreciable 195affinity for PITSMCBLS towards $\mathrm{Cr}^{3+}$ and $\mathrm{Fe}^{3+}$, suggests spontaneity of the adsorption 196process which does not require an external energy source for the system. $\Delta \mathrm{G}^{\circ}\left(\mathrm{Cr}^{3+}-14.187\right.$ to 197-14.832 and $\mathrm{Fe}^{3+}-14.369$ to $-14.843 \mathrm{kJmol}^{-1}$ ). Consequently, $\Delta \mathrm{G}^{\circ}$ of $-15 \mathrm{~kJ} / \mathrm{mol}$ are connected 198with physical interaction between adsorption site and metal ions which was observed in this 199study to be less, whereas $-30 \mathrm{KJ} / \mathrm{mol}$ involves charge transfer from adsorbent surface to the 200metal ion to form a coordination bond. This is a total deviation from the results obtained in 201this work. The positive values: $\Delta \mathrm{H}^{\circ}\left(\mathrm{Cr}^{3+} 5.345\right.$ and $\left.\mathrm{Fe}^{3+} 0.000 \mathrm{KJmol}^{-1}\right)$, suggest variation of 202enthalpies accompanying sorption of metal ions on the PITSMCBLS (indicating an 203endothermic process) which is facilitated by higher temperatures. The positive entropy 
204changes: $\Delta \mathrm{S}^{\circ}\left(\mathrm{Cr}^{3+} 64.459\right.$ and $\left.\mathrm{Fe}^{3+} 47.421 \mathrm{Jmol}^{1} \mathrm{~K}^{1}\right)$ is characterised by irregular increase in the 205randomness at the composite material-solution interface during adsorption procedure of the 206system (Zhiguang et al., 2011). The results above were characterised by chemisorption 207process, favoured at higher temperatures. The thermodynamic parameters considered are in 208harmony with the work of Nizam and Zeyad (2009).

209

\section{Table 3: Adsorption Thermodynamics for polysiloxane Immobilized 211Thiosalicylic/Mercaptoethanol $212 \quad$ Bi- Ligand System}

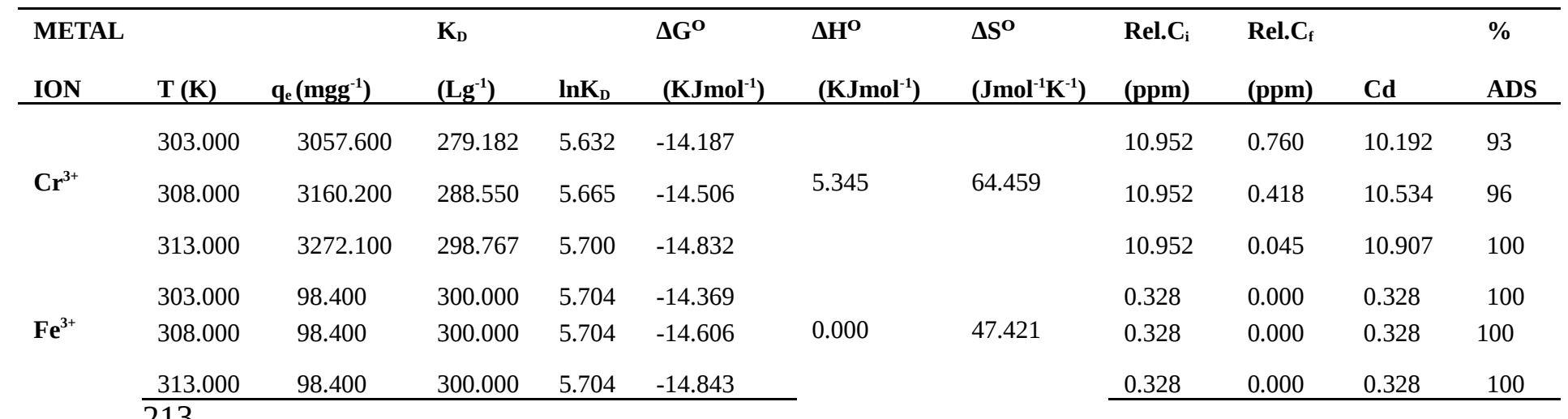

\section{Conclusion}

215The PITSMCBLS has been prepared by hydrolytic polycondensation of 216tetraethylorthosilicate with a mixture of 3- chloropropyltrimethoxysilane, methanol and 217sodium hydroxide as a catalyst. The instrumental analysis of FTIR, SEM and EDX 218confirmed that the ligands were chemically immobilized to the polysiloxane network. The 219PITSMCBLS showed high potential for the extraction of $\mathrm{Cr}^{3+}$ and $\mathrm{Fe}^{3+}$ at an optimum $\mathrm{pH}$ of 2206.0 in the tannery wastewater. Extraction of metal ion increased with increase in the 221adsorbent dose and temperature respectively. The thermodynamic parameters suggest a 222spontaneous and an endothermic affinity of the chelating ligand. 
223Authors' Contributions: This study was conducted between all the authors (BH, POU, 224SIRO, ASa, MBB and ASi). Author POU and BH got the concept and design of the study. 225The laboratory investigation, analysis and manuscript draft was done by BH and SIRO. The 226statistical analysis was done by ASi and POU. ASa and MBB participated in the laboratory 227work. The final version was written by BH and SIRO. SIRO and POU critically reviewed the 228manuscript for important intellectual content. All the authors gave final approval of the 229revised version for publication.

230Conflicts of Interest: The authors declare no conflict of interest.

231Funding: This research did not receive any specific grants from funding agencies in the 232public, commercial, or not-for-profit sectors.

233Acknowledgements: The authors are grateful to members of the scholars and technicians of 234the Department of Pure and Industrial Chemistry, University of Nigeria, Nsukka, Nigeria, for 235their moral support and technical assistance during the course of this research. Thanks to the 236Information Technology Department of SIRONigeria Global Limited, Abuja, Nigeria, for 237their role in the manuscript type setting.

\section{References}

2401. Abdussalam Salhin Mohammad Ali, Norfarhah Abdul Razak; Ismail Ab Rahman 241 (2012).Study on the Preparation of a Sol-Gel Sorbent Based Thiosemicarbazone for 242 Selective Removal of Heavy Metal Ions. World Applied Sciences Journal, 16(8): $243 \quad 1040-1047$.

2442. Ayoub G.M., Hamzeh A., Semerijian L. (2011). Post treatment tannery wastewater using 245 lime/bittern coagulation and activated carbon adsorption. Desalination. 273: 359246 365. 
2473. Bernard, E. and Jimoh, A. (2013).Adsorption of $\mathrm{Pb}, \mathrm{Fe}, \mathrm{Cu}$, and $\mathrm{Zn}$ from Industrial 248 Electroplating Wastewater by Orange Peel Activated Carbon. International Journal 249 of Engineering and Applied Sciences. 4 (2):95-103.

2504. Brad Busche, Robert Wiacek, Joseph Davidson, View Koonsiripaiboon, Wassana 251 Yantasee, Shane Addleman R, Glen E. Fryxell (2009). Synthesis of nanoporous 252 iminodiacetic acid sorbents for binding transition metals. Inorganic Chemistry 253 Communications 12:312-315.

2545. Bulus Habila, Ezeh Emmanuel Chidiebere, Danladi Hassana, Igbehinadun Olajide 255 Joseph, Shekarri Tachye Bwankhot (2018). Determination of heavy metals in 256 tannery wastes. International Journal of Agricultural and Biosystems Engineering 257 3(3): 78-81

2586. Durai G and Rajasimman M (2001). Biological Treatment of Tannery Wastewater - A 259 Review. Journal of Environmental Science and Technology 4 (1): 1 -7.

2607. El-Ashgar, N M (2009). Extraction and Pre-concentration capacity of bi-functionalized 261 diamine -thiol polysiloxane immobilized ligand system towards some divalent 262 cations. Journal of Iran Chem. Soc., 6 (4):823-830.

2638. Evangelo Min H, Ebel M, Chaeffer A (2007). Chelate Assistant Phyto Extraction of 264 Heavy Metals from Soil. Effect, Mechanism, Toxicity and Fate of Chelating Agents. 265 Chemosphere, 68: 989-1004.

2669. Flavio A. Pavan, Tamia M H Costa, Edilson V. Benvenutti (2003) Adsorption of $\mathrm{CoCl}_{2}$, $267 \mathrm{ZnCl}_{2}$ and $\mathrm{CdCl}_{2}$ on Aniline/Silica Hybrid Material Obtained by Sol-Gel Method. $268 \quad$ Colloids and Surfaces A: Physicochemical Engineering Aspects 226: 95-100.

26910. Ganesh R., Balaji G., Ramanujam R.A. (2006). Biodegradation of tannery wastewater 270 using sequencing batch reactor-respirometric assessment. Bioresources Technology. 271 97: 1815-1821.

27211. Horsfall, M.J., Abia, A.A. and Spiff, A.I. (2006). Kinetic Studies on the Adsorption of $273 \mathrm{Cd}^{2+}, \mathrm{Cu}^{2+}$ and $\mathrm{Zn}^{2+}$ Ions from Aqueous Solutions by Cassava (Manihot esculenta) 274 Tuber Bark Waste. Journal Bioresource Technology, 97 (35): 283-291.

27512. Igiri B.E., Okoduwa S.I.R., Idoko G.O., Akabuogu E.P., Adeyi A.O., Ejiogu I.K. (2018). 276 Toxicity and bioremediation of heavy metals contaminated ecosystem from tannery 277 wastewater: a review. Journal of Toxicology, $\quad$ Doi: $278 \quad$ https://doi.org/10.1155/2018/2568038

27913. Islam, B I; Musa, A E; Ibrahim, E H; Salma A.A Sharafa and Babiker M. Elfaki (2014). 280 Evaluation and characterization of tannery wastewater. Journal of Forest Products 281 and Industries, 3(3), 141-150

28214. Issa M. El-Nahhal, Basher A. El-Shetary, Kamal A. R Salib, Nizam M. El- Ashgar, 283 Ahmed M. El- Hashash (2010). Uptake of divalent metal ions $\left(\mathrm{Cu}^{2+}, \mathrm{Ni}^{2+}\right.$ and $\left.\mathrm{Co}^{2+}\right)$ 
284 by polysiloxane immobilized triamine- thiol and thiol-acetate ligand system. $285 \quad$ Analytical Letters 34 (12):2189-2202

28615. Issa M. El-Nahhal, Jane Jie Yang, Issuer Chuang, Gary E Maciel (1996). Synthesis of 287 solid state NMR structural characterization of polysiloxane immobilized thiol and 288 thiol-amine ligands. Journal of Non-Crystalline Solids 208:105-118.

28916. Issa M. El-Nahhal, Nizam M. El- Ashgar, Asmaa Abu- Shawish, Mona Abed El-Aziz 290 Ahmed, Florence Babonneau (2015). Template synthesis of immobilized291 polysiloxane diamine- thiol tetraacetic acid biligand system and its application for 292 determination of metal ions. phosphorus, sulphur, silicon and the related elements. 293 DOI: 10. 1080/104236507.2015.101.2667.

29417. Jahan, M. A. A., Akhtar N., Khan, N. M. S., Roy, C. K., Islam, R. and Nurunnabi 295 (2014). Characterization of tannery wastewater and its treatment by aquatic 296 macrophytes and algae. Bangladesh Journal of Science and Industrial Research, 297 49(4), 233-242.

29818. Machado M.D., Janssens S., Soares H.M., Soares E.V. (2009). Removal of heavy metals 299 using brewer's yeast strain of Saccharomyces cerevisiae, advantage of using dead $300 \quad$ biomas. Journal of Applied Micobiology. 106: 1792-1804.

30119. Mona A. Ahmed, Asmah A. Abu Shaweesh, Nizam M. El-Ashgar, Issa M. El-Nahhal, 302 Mohammed M, Chehimi, Florence Babonneau (2016). Synthesis and 303 characterization of immobilized- polysiloxane monoamine-thiol triacetic acid and its 304 diamine and triamine derivatives. Journal of Sol Gel Sci Technol 78:660-672.

30520. Muthukkauppan M, and Parthiban P (2018).A study on the physicochemical 306 characteristics of tannery effluent collected from chennai. International Research $307 \quad$ Journal of Engineering and Technology (IRJET)05 (03): 24-28.

30821. Nizam M. El-Ashgar, Zeyad J. Yasseen (2009). Complexation and Thermodynamic 309 Studies of Polysiloxane Iminobis (N-Diethylenediamineacetamide) Ligand System $310 \quad$ with Some Transition Metal Ions. Physical Chemistry an Indian Journal 4(2): 7131176.

31222. Okoduwa S.I.R., Adegbe E., Okoduwa U.J., Igiri B.E., Enang I.A. (2019). 313 Characterization of toxic pollutants in leather tannery effluents discharge at 314 Challawa industrial area, kano state, Nigeria. Chemical Society of Nigeria $42^{\text {nd }}$ 315 annual international conference and $4^{\text {th }}$ African Conference on Research in 316 Chemistry Education. Book of Abstract. CES405, pp 259

31723. Okoduwa S.I.R., Igiri B., Udeh C.B., Edenta C., Gauje B. (2017). Tannery effluents 318 treatment by yeast species isolates from watermelon. Toxics. 5,6; 319 doi:10.3390/toxics5010006 
32024. Okolo V.N., Olowolafe E.A., akawu I., Okoduwa S.I.R. (2016). Effects of industrial 321 effluents on soil resources in challawa industrial area, kano nigeria. Journal of 322 Global Ecology and Environment.5(1);1-10

32325. Onukak I.E., Mohammed-Dabo I.A., Ameh A.O., Okoduwa S.I.R., Fasanya O.O. (2017).

324 Production and characterisation of biomass briquette from tannery solid waste.

$325 \quad$ Journal of Recycling, 2(4):2313-2314

32626. Parimalam Ramachandran, Raj Vairamuthuand Sivakumar Ponnusamy (2011).

327 Adsorption isotherms, kinetics, thermodynamics and desorption studies of reactive

328 orange16 on activated carbon derived from ananas comosus (l.) carbon. ARPN

329 Journal of Engineering and Applied Sciences. 6, (11):15-26.

33027. Piotr Grzesiak, Joanna Lukaszyk, Elzbieta Gabala, Joanna Kurczewska, Grzegorz

331 Schroeder (2016). The influence of silica functionalized with silanes on migration of

332 heavy metals in soil. Polish Journal of Chemical Technology, 18 (1):51-57.

33328. Rajashree Kobiraj; Neha Gupta; Atul Kumar Kuswaha; Chattopadhyaya M. C (2012).

334 Determination of equilibrium, kinetics and thermodynamic parameters for

335 adsorption of brilliant green dye from aqueous solutions onto eggshell powder.

336 Indian Journal of Chemical Technology 19:26-31.

33729. Sekhararao Gulipalli CH., Prasad, Kailas B., Wasewar, L (2011). Batch study, 338 equilibirum and kinetics of adsorption of selenium using rice husk ash (RHA).

$339 \quad$ Journal of Engineering Science and Technology. 6 (5): 586 - 605

34030. Senthil Kumar P and Kirthika K. (2009) Equilibrium and kinetic study of adsorption of

341 nickel from aqueous solution onto bael tree leaf powder. Journal of Engineering

$342 \quad$ Science and Technology 4 (4):351-363.

34331. Shahida Parveen, Ram Bharose and Dharam Singh (2017).Assessment of physico-

344 chemical properties of tannery waste water and its impact on fresh water quality

$345 \quad$ International Journal of Current Microbiology and Applied Science.6(4): 18793461887.

34732. Vijayakumar G, Tamilarasan R, Dharmendirakumar M (2012). Adsorption, kinetic, 348 equilibrium and thermodynamic studies on the removal of basic dye rhodamine-B 349 from Aqueous Solution by the Use of Natural Adsorbent Perlite. Journal of Matter $350 \quad$ and Environmental Science. 3 (1):157-170.

35133. Vlasova N.N., Oborina E.N., Grigoryeva Yu O., Voronkov M.G. (2013). Organosilicon 352 ion-exchange and complexing adsorbents. Russian Chemical Review 82 (5): 449353464.

35434. Zhiguang Ma, Na Di, Fang Zhang, Peipei Gu, Suwen Liu and Pan Liu (2011). Kinetic 355 and thermodynamic studies on the adsorption of $\mathrm{zn}^{2+}$ onto chitosan-aluminium oxide 356 composite material. International Journal of Chemistry 3 (1):18-23. 
- Polysiloxane-Immobilized thiosalicylic-mercaptoethanol ligand system was prepared.

- Scanning Electron Microscopy of the ligand system gave mesopore particle size.

- A negative $\Delta \mathrm{G}^{\circ}$ and positive values for $\Delta \mathrm{H}^{\circ}$ and $\Delta \mathrm{S}^{\circ}$ were obtained

- High extraction potential of $\mathrm{Cr}^{3+}$ and $\mathrm{Fe}^{3+}$ in tannery wastewater was exhibited.

- $\quad$ This method would be more effective in detoxifying $\mathrm{Cr}^{3+}$ and $\mathrm{Fe}^{3+}$ from wastewater. 
Synthesis_Characterization_of_Immobilized_Thiosalic... (266.29 KiB) view on ChemRxiv • download file 
Other files

Manuscript=BH.pdf (309.66 KiB)

view on ChemRxiv • download file 